\title{
Teaching competences in Italian universities: an attempt of classification to inform professional development processes
}

\author{
Felisatti, Ettore ${ }^{a}$; Aquario, Debora ${ }^{a}$, Clerici, Renata ${ }^{b}$; Da Re, Lorenza ${ }^{a}$; Paccagnella, \\ Omar $^{\mathrm{b}}$ and Serbati, Anna ${ }^{\mathrm{a}}$ \\ ${ }^{a}$ Department of Philosophy Sociology Education and Applied Psychology, University of \\ Padova, Italy, ${ }^{\mathrm{b}}$ Department of Statistical Sciences, University of Padova, Italy.
}

\begin{abstract}
How we can improve the quality of teaching in the university degree courses? What are the professors'practices and the beliefs about their role in the students' learning process? A group of spokespersons of seven Italian Universities has carried out an integrate sources study to answer those questions and to define a programme of activities for developing didactic skills of the teachers. This paper aims to illustrate the design and the results of a research project which involved 4,289 university professors (59\% of the target population), who were teaching courses at bachelor and master level during the academic year 2014/15. The data were directly gathered by a CAWI questionnaire which was distributed to the whole teaching staff; the survey results were linked to administrative data related to the educational offer and students' evaluation of teaching in the same academic year. The results were summarized using some indicators, which showed the diffusion of good practices of teaching, support needs, beliefs, interest and availability of the respondents. We verified the reliability of these indicators and, by means of them, we identified sub-groups of areas of expertise and needs to involve teachers in appropriate different and integrated activities, directed to develop teachers' professional competences.
\end{abstract}

Keywords: Academic teaching;teaching innovation;educational practices; sources integration; questionnaire validation; teachers professional development. 


\section{Introduction}

Improvement and innovation in teaching are constant elements in universities all over the world. Major changes nowadays concern the use of technology, the internationalisation, the overall teaching process and system (EUA, 2015). A crucial aspect is teaching effectiveness and its impact on the quality of learning (Biggs, 2011). Teachers are called to use active learning strategies, to involve students in the classroom, to promote meaningful learning. In order to do that, competences in designing learning outcomes, choosing and implementing teaching and learning methods as well as strategies for assessment and evaluation are required. Therefore, academic institutions are responsible for promoting staff development programs to enhance teaching competences (OECD, 2012; High Level Group on the Modernisation, 2013; ENQA, 2015).

The Italian scenario, unfortunately, appears late in this field (Felisatti, 2016). The University of Padova in 2013 promoted a first experience with the project "PRODIDPreparazione alla professionalità docente e innovazione didattica" aimed at developing an integrated system (Diamond, 2002) to improve teaching competences and academic innovation. PRODID project promoted a research-based approach to creating training programs, faculty learning communities, pilot experimental contexts where teaching innovation could be tested and monitored (Felisatti \& Serbati, 2014). Following an evidence-based approach, the project aimed at highlighting the teachers' needs, beliefs and practices of teaching and learning, which may constitute a privileged context for the development of innovative teaching activities within the institution. A questionnaire has been drafted, inspired by the Framework of teaching (Tigelaar et al., 2004); the dimensions investigated have been the following: The Person as Teacher, Expert on Content Knowledge, Facilitator of Learning Processes (developer, counsellor, evaluator), Organiser, Scholar/Lifelong Learner. The questionnaire sections were organised as follows: the first section focused on "practices" developed in teaching activities in the previous academic year; teachers were asked to reply to the questions referring to those real activities carried out previously. The second section deepened teachers' "beliefs" about teaching in higher education, and the third section focused on teachers' "needs". Considering that PRODID aimed at designing and testing training programs for teachers' professional development, it seemed crucial to understand the real needs of teachers in order to provide the best support possible for them and for the improvement of pedagogical competences. Therefore, questionnaire results were used to define teachers' profiles, based on previous experience, beliefs, interests, needs, availability, to develop tailored activities.

After this first project at University of Padova, the questionnaire has been slightly changed and it is now used for a national research called "Didactics and Teaching in University", carried out by 7 Italian Universities (Bari, Camerino, Catania, Firenze, Foggia, Genova, 
Torino), with the aim of validating the instrument and guiding institutional decisions on continuing professional development actions.

The aim of this contribution is to introduce the main features of this innovative survey and show how the collected data may be used to provide a first classification of teachers' areas of expertise and needs.

\section{Method}

The survey "Didactics and Teaching in University" aims at testing the capability of a questionnaire to describe a picture of the teaching experience in use among Italian Universities, and classifying their practices, beliefs and needs, with regard to their teaching activities developed in the university classrooms. This computer-assisted web interviewing survey is integrated with administrative data, related to the teachers and the educational offer of the different academic institutions. The experimentation involved 7 Italian Universities, located in different geographical areas and having various dimensions, according to the number of students and teachers. Two units of analysis may be specified: the university professor and the didactic activity (DA) (at least 20 hours).

The reference population is composed by all professors of all Universities. Therefore, the study involved 7,278 professors and 11,948 DAs were surveyed in the questionnaire section that measures the didactic practices used in the teaching activities. The involved universities provided the administrative information, which allowed to adequately qualify the characteristics of each teacher (i.e. gender, age, position, etc.), DA and research-didactic context (i.e. name of the courses taught by each teacher in the previous academic year, degree level, number of hours, etc.). The online survey took place between June and August 2016. Teachers and DAs data were linked to each questionnaire, by specific procedures of management of the personal identification code provided for the used sofware (LimeSurvey). This allowed to manage the invitations, organize the requests, associate to every teacher their attributes of interest, guaranteeing the anonymity of the information. These attributes concerned the appropriate DA for every respondent, the degree course of the considered DA, the year of course, the numbers of hours of the DA (each teacher could respond to the questions, referring to their own didactic activity taught in the previous academic year, which automatically appeared in the questionnaire).

The questionnaire consists of three sections. The first section is composed by 10 dichotomic items. They are proposed to the respondents for each of the DAs developed by them $(\max 2)$ and investigate the reported usual didactic practices of each of the considered DAs $(0=$ No; $1=$ Yes). The second part aims at understanding what are the beliefs and the needs that each teacher feels crucial is in his/her DA. Differently from the first section, this part focuses on the professor and it is composed by 23 auto-anchoring items: the answers of 
each proposed statement have the same scale from 1 (not agree at all) to 7 (fully agree). In the third section the availability of the teacher to a follow-up contact is assessed. Furthermore, this last section proposes some open questions around possible innovations, critical points, useful supports for a future improvement. For further explanations about the questionnaire administration and the item contents see Dalla Zuanna et al., 2014. A preliminary phase of pre-test allowed to check the content, the form, and the technical aspects of the survey tool. Particular attention has been given to the communication process and the monitoring of the attendance to the survey, for instance through specific interventions and focused requests.

\section{Results}

The total number of completed questionnaires is 4,289, leading to a response rate (with respect to the teacher population) of 59\%. Disaggregating it by teachers' features (gender, age, position and so on), we can observe that women were more likely to answer than men, as well as a clear negative gradient by age (the younger the higher): the response rate moves to $68 \%$, for respondents aged from 30 to 45 years, to $31 \%$ for tearchers older than 70 years. Respondents were asked to complete the first part of the questionnaire for at least one of their DAs: 2,760 teachers provided answers for two DAs, while 1,529 to just one DA (the average value is therefore 1.6 activities per respondent). Overall, 7,049 DAs were investigated.

Table1. Dimensions of the first part of the questionnaire ("Teaching practices")

\begin{tabular}{ccc}
\hline $\begin{array}{c}\text { MACRO- } \\
\text { DIMENSIONS }\end{array}$ & $\begin{array}{c}\text { DIMENSIONS } \\
\text { OF THE QUESTIONNAIRE }\end{array}$ & $\begin{array}{c}\text { \% OF USE AND \# OF } \\
\text { ITEMS IN EACH } \\
\text { DIMENSION }\end{array}$ \\
\hline Facilitator & Teaching and learning methods & $63.5(2)$ \\
of learning processes & Use of technologies in teaching practices & $46(3)$ \\
Organiser & Assessment and evaluation methods & $59.5(2)$ \\
Scholar/lifelong learner & Integration of teaching practice in the curriculum & $68(2)$ \\
\hline
\end{tabular}

Table 1 summarises the dimensions underlying the practices analysed in this part of the questionnaire (for length constraints, reporting descriptive statistics for the answers to each question was unfeasible). One of the two items investigating the "Integration of teaching practice in the curriculum" show the largest proportion of positive answers $(90 \%)$, signalling that respondents strongly believe their teaching activities play an important role in the general educational path they are involved to. On the other hand, looking at the answers to all questions of the "Use of technologies in teaching practices" dimension, it is 
very high the proportion of teachers who do not produce technological (multimedia) materials (more than $50 \%$ of teachers) or exploit advanced web opportunities (even $74 \%$ of them). The low proportion of positive answers (lower than 50\%) to similar questions included in the "Integration of teaching practice in the curriculum" and in the "Teaching and learning methods" dimensions reveals an overall weak use of both the contribution of external experts as a part of the lessons and the fulfilment of teaching activities in coordination with other teachers teaching similar topics.

According to the macro-dimensions introduced (Tigelaar et al., 2004), Table 2 lists the seven dimensions investigated in the second part of the questionnaire (Teaching beliefs and needs), as well as the number of items within each dimension. Each item basically shows an asymmetric frequency distribution (median value has a range between 5 and 7), apart from the "Assessment and evaluation methods" dimension, which items roughly present symmetric distributions (the average value is indeed around 4).

On the one hand, the passion for research and the passion for teaching report the highest evaluations (particularly the first one, where the median is equal to 7 in two out of three items), with a positive relationship (in other words, few respondents - roughly $10 \%$ - are inclined to define themselves as "just" teachers or "just" researchers). On the other hand, the largest variability may be observed among the items identifying the "Reflection and strategies for improvement" dimension. The largest proportion of missing values are collected by the item that asks about the use of the target language (English) within the "knowledge transmission" dimension.

Table2. Dimensions of the second part of the questionnaire ("Teacher beliefs and needs")

\begin{tabular}{ccc}
\hline MACRO-DIMENSIONS & $\begin{array}{c}\text { DIMENSIONS } \\
\text { OF THE QUESTIONNAIRE }\end{array}$ & $\begin{array}{c}\text { MEAN AND \# OF } \\
\text { ITEMS IN EACH } \\
\text { DIMENSION }\end{array}$ \\
\hline The person as teacher & Passion for research & $5.7(3)$ \\
Facilitator of learning & Teaching and learning methods & $5.2(4)$ \\
processes & Assessment and evaluation methods & $4.1(3)$ \\
Expert on content knowledge & Focus on students' needs & $4.6(3)$ \\
Scholar/lifelong learner & Knowledge transmission & $6.1(2)$ \\
The person as teacher & Reflection and strategies for improvement & $4.2(4)$ \\
\hline
\end{tabular}

All answers are then classified in six categories, according to some criteria defined through the combination of six different indicators, five of them obtained from the collected answers. The indicators are:

1) Interest. It is calculated exploiting the answers to the items of the "Reflection and strategies for improvement" dimension from the second part of the questionnaire ("Teaching beliefs and needs"). A factor analysis on these items is performed and the factor 
score for each respondent is then computed. The interest indicator is expressed by a 5-point scale: low (21\%), middle-low (11\%), middle (34\%), middle-high (14\%), high (20\%).

2) Need to support. It is calculated exploiting the answers to the items of the "Focus on students' needs" dimension from the second part of the questionnaire ("Teaching beliefs and needs"). Similarly to the interest indicator, a factor analysis on the items is performed and the factor score for each respondent is computed. The need to support indicator is expressed by a 5-point scale: low (16.5\%), middle-low (10\%), middle (42.5\%), middle-high (17\%), high (14\%).

3) Contact willingness. It is calculated exploiting the answer to the last question of the questionnaire; it is expressed on a binary variable, willing (62\%) vs unwilling teacher (38\%).

4) Technological practices. It is calculated exploiting the answers to the items from 7 to 9 from the first part of the questionnaire ("Teaching practices"). It is expressed as the sum of the positive answers to these items (the average value is equal to 1.46).

5) Methodological/learning assessment practices. It is calculated exploiting the answers to the items from 1 to 6 from the first part of the questionnaire ("Teaching practices"). It is expressed as the sum of the positive answers to these items (the average value is 1.55).

6) Student's evaluation of teaching (SET). It is calculated exploiting administratrive data, provided by each University and based on the answers to the survey measuring the students' opinion on the DAs. More specifically, the focus is on two particular questions ("Does the teacher stimulate interest towards the topic?" and "Does the teacher clearly explain?"), which are identified as the most important observed items of a latent variable related to the efficacy of (teacher) didactics measuring the student satisfaction (Bassi et al. 2017). It is computed comparing the median value of the answers to each item of each DA. The SET indicator is then expressed by a 3-point scale: low (9\%), middle (38\%), high $(53 \%)$ satisfaction.

These indicators are combined in order to define six categories grouping different levels of expertise, needs and interest/willing to improve:

1) Strong expertise and interest: high or middle-high interest, high technological and methodological/learning assessment practices, high level of students' satisfaction and teacher' willingness to be contacted.

2) Strong expertise and medium interest (not classified as 1): high technological and methodological/learning assessment practices, high or medium level of students' satisfaction, further classified as willing and unwilling to be contacted.

3) Young expertise (not classified as 1 and 2): newly recruited teachers on the tenure track and younger than 45 years, further classified as willing and unwilling to be contacted.

4) Soft expertise and strong interest/need of support (not classified as 1, 2 and 3): high, middle-high or middle interest and high, middle-high or middle need to support, further classified as willing and unwilling to be contacted. 
5) Other willingness (not classified in any of the previous groups): general willingness in being contacted.

6) Other (the remaining answers).

Table 3 shows the classification of the whole sample according to the aforementioned criteria. The largest group is composed by group 4 (about 37\%), followed by the group 2 (23\%). Group 1 comprises about $6 \%$ of the teachers' answers as a whole.

Table 3. Classification of different levels of expertise, needs and interest/willingness to improve

\begin{tabular}{|c|c|c|}
\hline Group & & Proportion (\%) \\
\hline 1.Strong expertise and interest & & 5.7 \\
\hline \multirow[t]{2}{*}{ 2.Strong expertise and medium interest } & Willing & 14.8 \\
\hline & Unwilling & 8.1 \\
\hline \multirow[t]{2}{*}{ 3.Young expertise } & Willing & 2.5 \\
\hline & Unwilling & 1.9 \\
\hline \multirow[t]{2}{*}{ 4.Soft expertise and strong interest } & Willing & 25.7 \\
\hline & Unwilling & 11.5 \\
\hline 5.Other willingness & & 13.2 \\
\hline 6.Other & & 16.6 \\
\hline
\end{tabular}

\section{Discussion}

The study allowed to test the questionnaire aimed at understanding teachers' practices, beliefs and needs and classifying them to better tailor staff development programs. The instrument will be available for other Italian institutions interested in collecting a first picture of teaching expertises and desires of support in order to inform decisions regarding training processes. The key areas identified - based on experience, support needs, beliefs, interest and availability - help to propose training actions balanced between individual availabilities and institutional objective to qualify teachers. In the PRODID experience, the results of the questionnaire were supported by a second research step based on a qualitative investigation. Interviews and focus groups deepened and better informed the choice of staff development actions as well as contents and topics to be addressed and discussed.

PRODID project proposed three staff development actions, that may be of inspiration for other Italian universities. Teachers study group with senior professors was devoted to improving mentoring, coaching, peer-observation, peer-assessment in order to train teachers who declared to be already competent and interested in teaching and learning to become pedagogical expert who can support colleagues in their department. Junior staff development program was offered to newly recruited teacher to develop basic competences in designing, implementing and evaluating teaching and learning. Workshops and events on specific topics provided opportunities to learn with colleagues methods and techniques such 
as problem-based learning, active learning strategies, flipped classroom, educational technologies, etc. (for a detailed description of staff development activities, please see the project publication: Felisatti \& Serbati, 2017).

\section{References}

Bassi, F., Clerici, R., Aquario, D. (2017). Students' evaluation of teaching at a large Italian university: validation of measurement scale, Electronic Journal of Applied Statistical Analysis, vol. 10 (1), 93-117.

Biggs, J. e Tang, C. (2011), Teaching for quality learning at University (4th ed.), Maidenhead, Open University Press, McGraw Hill Education.

Dalla Zuanna, G., Clerici, R., Martinoia, S., Paccagnella, O., Paggiaro, A., Pierobon, S. (2016). Evaluative research in education: a survey among professors of University of Padova, Excellence and Innovation in Teaching and Learning. Research and practices, 1(1), 17-34.

Diamond, R.M. (2002). Faculty, Instructional and organizational development: options and choices. In K.H. Gillespie, L. Hilsen, E.C. Wadsworth (Eds). A guide to faculty development. Practical advices, examples and resources (2-8). San Francisco: JossyBass.

ENQA (2015). Standards and Guidelines for Quality Assurance in the European Higher Education Area. Available at: http://www.enqa.eu/index.php/home/esg/ (accessed 28 January 2017).

EUA (2015), Trends 2015: Learning and Teaching in European Universities, Belgio.

Felisatti, E. (2016). Modelli e strategie per la formazione del docente universitario. In: Rivoltella P.C., Felisatti E., Di Nubila R.D., Notti A.M., Margiotta U. (Eds). Saperi pedagogici e pratiche formative. Traiettorie tecnologiche e didattiche dell'innovazione (131-147). Lecce: Pensa MultiMedia.

Felisatti, E., \& Serbati, A. (2014). The professional development of teachers: from teachers' practices and beliefs to new strategies at the university of Padua, Proceedings of the ICED conference Educational development in a changing world, Stockholm, 1618 June 2014, available online at: http://www.iced2014.se/proceedings.shtml.

Felisatti, E., \& Serbati, A. (2017) (Eds). Sviluppare la professionalità docente e innovare la didattica universitaria. Milano: F. Angeli.

Hénard, F., \& Roseveare, D. (2012). Fostering quality teaching in higher education: Policies and Practices. An IMHE Guide for Higher Education Institutions.

High Level Group on the Modernisation of Higher Education (2013), Report to the European Commission on Improving the qualityof teaching and learning in Europe's higher education institutions, Belgium: European Union.

Tigelaar, D.E.H., Dolmans, D.H.J.M., Wolfhagen, I.H.A.P., Van Der Vleuten, C.P.M. (2004). The development and validation of a framework for teaching competencies inhigher education. Higher education, 48(2), 253-268. 